\title{
EFEKTIFITAS LATIHAN FISIK YOGA TERHADAP KADAR GULA DARAH SEWAKTU PADA DIABETES MELLITUS TIPE 2 DI KRAMAT- JAKARTA
}

\author{
${ }^{1}$ Maria Lousiana, ${ }^{2}$ Sr. Hermana, ${ }^{3} \mathrm{CB}$; Sondang Sianturi \\ 123Program Studi Keperawatan \\ STIK Sint Carolus \\ email: lousianasuwarno@gmail.com
}

\begin{abstract}
Diabetes mellitus type 2 is the most common type of diabetes found around the world. It is estimated in the year 2035 will occur explosion sufferers of diabetes mellitus. Uncontrooled Diabetes Mellitus may cause complications in organs - other organs such as: heart, kidneys and eyes. There are several treatments for controlling diabetes Mellitus, one of which is the physical exercises of yoga. This study aimed to investigate the effectiveness of physical yoga exercises against the respondent's blood sugar. This research is quasi alphabets experiment with the design of the intervention group pre test - post test. The Sampling method by using the Krejcie table population size (N) 55 and the number of samples (S) 48. Data analysis with Ordinal Regression and difference test. On this group intervention is done as much as once a week for 3 months. The statistical test used different test pretest and post test. Ordinal regression test results showing that yoga changes have an effect on blood sugar levels while (Pvalue 0.003). The wilxoson test results obtained $p=0.006$, meaning that there was a difference in blood sugar during before and after physical exercises of yoga. Conclusion of this study is physical exercise yoga is effective for lowering blood sugar levels in type $2 \mathrm{DM}$, then it is recommended that the Ministry of Health introduced this intervention, in the independent care of patients at home, so that patients can control their blood sugar levels
\end{abstract}

Keywords: Type 2 diabetes; blood sugar levels; physical exercises of yoga

\section{ABSTRAK}

Diabetes melitus tipe 2 merupakan tipe diabetes yang paling umum ditemukan di seluruh dunia. Diperkirakan pada tahun 2035 akan terjadi ledakan penderita diabetes melitus. Diabetes Mellitus tidak terkontrol maka dapat menimbulkan komplikasi pada organ - organ lain seperti : jantung, ginjal dan mata. Ada beberapa penatalaksanaan Diabetes Mellitus, salah satunya adalah latihan fisik yoga. Dalam penelitian ini, bertujuan agar diperoleh kejelasan tentang efektifitas latihan fisik yoga terhadap gula darah responden. Penelitian ini merupakan quasi eksperiment dengan desain kelompok intervensi pre test - post test.Metode Sampling dengan purposive sampling. Jumlah sampel adalah 48 sampel. Analisa data dengan uji beda dan Regresi Ordinal. Pada kelompok ini intervensi dilakukan sebanyak $1 \mathrm{x}$ dalam seminggu selama 12 minggu. Uji statistik yang digunakan adalah uji beda pre test dan post test. Hasil uji regresi menunjukkan bahwa yoga berpengaruh terhadap perubahan kadar gula darah sewaktu $(P=0,003)$. Pada uji beda wilxoson diperoleh hasil $p=0,006$, artinya terdapat perbedaan gula darah sewaktu sebelum dan sesudah latihan fisik yoga. Kesimpulan penelitian ini adalah latihan fisik yoga efektif untuk menurunkan kadar gula darah sewaktu pada DM Tipe 2, maka disarankan agar pelayanan 
kesehatan memperkenalkan intervensi ini, dalam perawatan mandiri pasien di rumah, sehingga pasien dapat mengontrol kadar gula darahnya.

Kata kunci: DM Tipe 2; kadar gula darah; latihan fisik yoga

\section{PENDAHULUAN}

Diabetes mellitus adalah sekelompok kelainan heterogen yang ditandai oleh kenaikan kadar glukosa dalam darah atau hiperglikemi ( Brunner and Sudddarth. 2007). Peningkatan diabetes di negara - negara berkembang dipengaruhi oleh perubahan gaya hidup karena peningkatan kemakmuran negara tersebut. Gaya hidup tradisional seperti mengkonsumsi karbohidrat komplek, rendah lemak jenuh, tinggi kalori dan tidak merokok mulai ditinggalkan dan digantikan dengan kebiasaan membeli makanan dengan kandungan karbohidrat sederhana, tinggi lemak jenuh yang menjadi faktor resikopenyebab diabetes. International Diabetes Federation pada tahun 2013 mengungkapkan, penderita diabetes di seluruh dunia mencapai 382 juta orang. Pada tahun 2035 penderita diabetes diperkirakan akan meningkat menjadi 592 juta orang. . Ini setara dengan sekitar 3 kasus baru dalam 10 detik, atau hampir 10 juta pertahun. Hasil Riset Kesehatan Dasar (Riskesdas) pada tahun 2008, menunjukkan prevalensi DM di Indonesia meningkat sampai 57 \%(Fatimah.2014 dalam jurnal Diabetes Melitus Tipe 2).

Pada tahun 2006 sebuah penelitian yang dilakukan Departemen IImu Penyakit Dalam Fakultas Kedokteran Universitas Indonesia melakukan Surveilans Faktor Risiko Penyakit Tidak Menular di Jakarta. Penelitian tersebut melibatkan 1591 responden, terdiri dari 640 laki - laki dan 951 perempuan. Hasil survei dilaporkan prevalensi DM (unadjusted) yang ditemukan di lima wilayah Jakarta 12,1
\%. (Setiadi, 2014). Penyakit diabetes di Indonesia dalam kurun waktu 30 tahun akan meningkat, akibat dari jumlah penduduk yang bertambah, penduduk usia lanjut bertambah, pendapatan tinggi, tekhnologi canggih yang mengakibatkan kurang gerak dan meningkatnya pelayanan kesehatan sehingga umur harapan hidup bertambah (Setiadi, 2014) .

Perbandingan penduduk akan mengalami perubahan, di mana penduduk usia dewasa dan usia lanjut lebih banyak dibanding tahun sebelumnya. Presentasi kasus diabetes lebih banyak terjadi pada usia dewasa dan usia lanjut (Setiadi, 2014). Diabetes melitus tergolong penyakit endokrin yang dalam jangka panjangdapat menyebabkan komplikasi kerusakan jaringan. Karena itu pola pengobatan tidak hanya kepada penanggulangan saja, tetapi dilakukan secara menyeluruh dengan pendekatan 4 pilar (Waspadji, 2011).

Upaya penatalaksanaan DM Tipe 2 ada empat pilar dimulai dengan pendekatan non farmakologi yaitu berupa pemberian edukasi diabetik, perencanaan makan/diet, olahraga serta obat antidiabetik. Olahraga adalah salah satu pilar dalam tatalaksana DM Tipe 2(Waspadji, 2011) . Hiperglikemia pada penderita diabetes melitus tipe 2 jika tidak dilakukan intervensi segera, dapat menjadi persisten dan menimbulkan komplikasi. Komplikasi dapat dicegah dengan melakukan olahraga aerobik. Olahraga aerobik merupakan jenis olahraga/ latihan fisik yang ditujukan untuk memperoleh tingkat ketahanan 
kardiovaskuler yang lebih efektif. Latihan fisik ini dilakukan secara bertahap, intensif dan intensitas yang rendah dengan durasi $30-60$ menit, (Waspadji, 2011).

Salah satu bentuk latihan aerobik untuk menurunkan kadar glukosa dalam darah adalah Yoga. Menurut Bindra, dkk dalam jurnalnya yang berjudul "Influence Of Pranayamas and Yoga-Asanas On Blood Glucose, Lipid Profile and HBA1C In Type 2 Diabetes menyebutkan dengan melakukan yoga dengan tekun dan teratur selama 30 - 45 menit, tiga kali seminggu selama 90 hari dapat menurunkan gula darah. Study ini dilakukan untuk mengetahui apakah latihan fisik yoga efektif untuk mempengaruhi kadar gula darah sewaktu pada diabetes tipe 2 .

\section{METODE}

Penelitian ini menggunakan metode kuantitatif quasi experiment dengan desain penelitian rancangan cross sectional. Kelompok tersebut akan diobservasi pre test latihan fisik yoga dan post test latihan fisik yoga. Populasi dalam penelitian adalah semua penderita diabetes mellitus dan yang beresiko, berusia 40-80 tahun, yang mengikuti latihan fisik yoga 60 menit dengan frekuensi latihan $1 \mathrm{x} /$ minggu selama 12 minggu. Jumlah sampel yang diambil dalam penelitian ini menggunakan tabel Krejcie ukuran Populasi (N) 55 dan ukuran Sampel (S) 48 dengan menggunakan teknik Nonprobability sampling yaitu purposive sampling. Penelitian dilakukan di Kramat Jakarta Pusat pada bulan Agustus 2015Nopember 2015.

Pengumpulan data dilakukan dengan menggunakan alat glukometer untuk pemeriksaan kadar gula darah, lembar observasi pelaksanaan latihan fisik yoga dan kadar glukosa darah. Glukometer yang digunakan adalah Easy Touch GCU karena hasilnya lebih cepat, lebih detail menunjukkan angka serta caranya lebih mudah digunakan. Lembar observasi digunakan untuk mencatat karakteristik responden, yang meliputi initial, umur, jenis kelamin, nomor telepon, riwayat DM tipe 2. Penelitian ini dianalisis dengan menggunakan Uji beda independen statistika non-parametrik, Uji yang digunakan adalah Wilcoxon yang merupakan uji perbedaan pre test dan post test yoga.

\section{HASIL}

Pada tabel 1 menunjukkan penelitian ini dilakukan pada responden berusia 40 - 80 tahun (total sampel 45) dengan latar belakang yang berbeda. Sebagian besar responden adalah perempuan. Latihan fisik yoga ini dilakukan oleh instruktur yoga professional. Latihan fisik yoga ini dilakukan selama 60 menit dengan frekuensi latihan $3 \mathrm{x} /$ minggu selama 12 minggu.

Pada output uji beda wilcoxon (tabel 3) kadar gula darah pre test dan post test latihan fisik yoga didapat tingkat significan 0,006 . Tingkat signifikan ini $<\alpha$ 0,05 , artinya Ha diterima, ada perbedaan antara gula darah pre test dan post test latihan fisik yoga. Hipotesa satu terbukti dengan angka signifikan 0,006 0,05. Perbedaan yang bermakna ini terlihat dalam angka kadar gula darah pre test yoga minggu ke-1 dan post test yoga minggu ke-12 . Kadar gula darah sewaktu mengalami perubahan, naik, turun dan tetap pada angka yang sama, sesuai karakteristik masing - masing responden. Perbedaan hasil gula darah sewaktu dipengaruhi oleh keadaan kesehatan masing - masing responden 
Tabel 1. Karakteristik responden, Analisis Pre dan Post Test

\begin{tabular}{llll}
\hline Variabel & & Frek & $\%$ \\
\hline Usia & 40-50 Thn & 8 & 17,8 \\
& $\mathbf{5 1 - 6 0}$ Thn & $\mathbf{2 1}$ & $\mathbf{4 6 , 7}$ \\
& $61-70$ Thn & 10 & 22,2 \\
& $71-80$ & 6 & 13,3 \\
\hline Jenis Kelamin & Perempuan & $\mathbf{4 0}$ & $\mathbf{8 8 , 9}$ \\
& Laki-laki & 5 & 11,1 \\
\hline Pre Test Yoga 1 & & & \\
\hline Gula Darah Sewaktu & $80-120$ & 27 & 60,0 \\
& $121-200$ & 10 & 22,2 \\
& $\mathbf{2 0 1 - 3 0 0}$ & $\mathbf{7}$ & $\mathbf{1 5 , 6}$ \\
& $\mathbf{3 0 1 - 3 2 5}$ & 1 & $\mathbf{2 , 2}$ \\
\hline GDS Post Test 12 & & & \\
\hline Gula Darah Terakhir & $80-120$ & 30 & $\mathbf{6 6 , 7}$ \\
& $121-200$ & 8 & 17,8 \\
& $201-300$ & 7 & 15,6 \\
\hline
\end{tabular}

Tabel 2. Hasil Analisis perbandingan nilai GDS Pre test 1 - Post test latihan fisik yoga dengan Uji Beda Wilcoxon.

\begin{tabular}{lllll}
\hline & & N & $\begin{array}{l}\text { Mean } \\
\text { Rank }\end{array}$ & $\begin{array}{l}\text { Sum of } \\
\text { Ranks }\end{array}$ \\
\hline GDS & Negative Ranks & 33a & 22,17 & 731,50 \\
langsung & Positive Ranks & 11b & 23,50 & 258,50 \\
setelah & Ties & 1c & & \\
latihan & Total & $\mathbf{4 5}$ & & \\
yoga k & & & & \\
12 - & & & \\
GDS Pre & & & \\
post hari & & & \\
1 & & & \\
\hline
\end{tabular}

Tabel 3. Uji Wilcoxon perbedaan GDS sebelum dan sesudah

\begin{tabular}{ll}
\hline & GDS setelah latihan yoga \\
& k 12 - GDS Pre post hari 1 \\
$Z$ & $-2,761 \mathrm{~b}$ \\
Asymp. Sig. (2-tailed) & $\mathbf{0 0 6}$ \\
\hline
\end{tabular}

Tabel 5. Test of Parallel Linesa, Penilaian kemaknaan usia, jenis kelamin dan latihan fisik yoga

\begin{tabular}{lllll}
\hline Model & -2 & $\begin{array}{l}\text { Chi- } \\
\text { Log } \\
\text { Likelihood }\end{array}$ & df & Sig \\
& & & \\
\hline $\begin{array}{l}\text { Null } \\
\text { Hypothesis } \\
\text { General }\end{array}$ & $48,373 \mathrm{~b}$ & $224,098 \mathrm{c}$ & 96 &, 000 \\
& & & & \\
\hline
\end{tabular}

seperti nyeri lutut, nyeri pinggang, pusing, mual, kesemutan dan keluhan lain. Keluhan - keluhan ini berpengaruh terhadap kemampuan melakukan setiap gerakan dalam yoga.

\section{PEMBAHASAN}

Pada tabel di atas menunjukkan hasil uji Parallel lines perubahan kadar gula darah sewaktu. Nilai parallel line menunjukkan Nilai Pvalue $0,000<0,05$ artinya $\mathrm{Ha}$ diterima. Kesimpulan dari hasil yang didapat latihan fisik yoga mempunyai makna yang besar dalam menentukan perubahan kadar gula darah sewaktu. Secara umum gangguan metabolik yang dialami pasien dengan diabetes mellitus terkadang tidak berespon terhadap obat antidiabetik dan insulin. Alternatif pengobatan dilakukan dengan pendekatan strategi natural/alami (contohnya dengan modifikasi diet, posture yoga, latihan nafas dengan tujuan relaksasi pikiran)

Tabel 4. Uji Parameter Estimates, menilai kereratan usia, jenis kelamin dan latihan fisik yoga terhadap kadar gula darah sewaktu

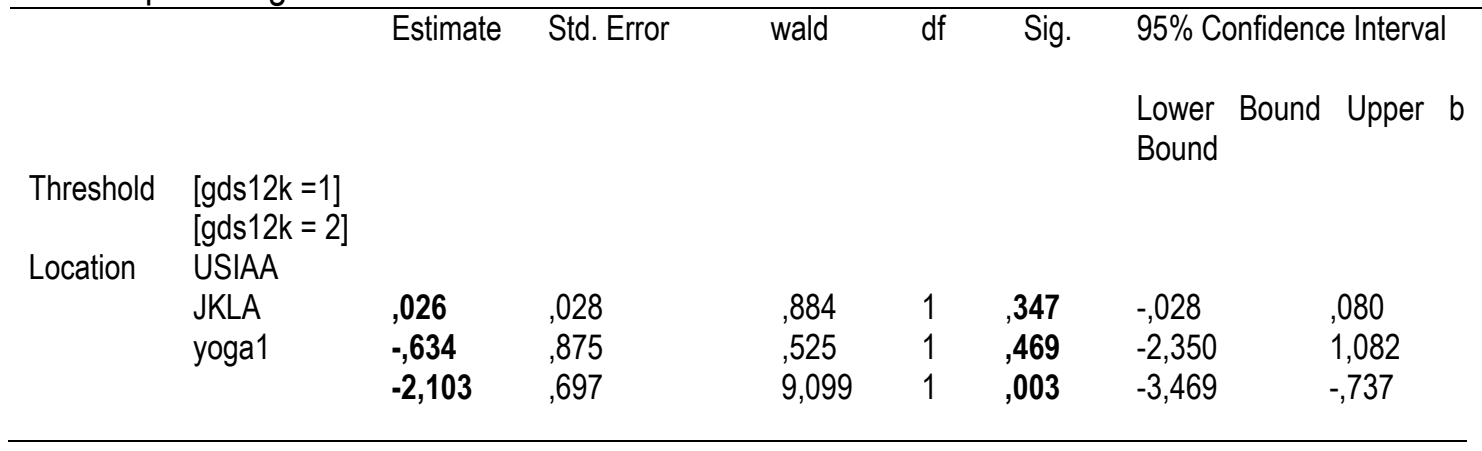


digunakan sebagai therapi komplementer untuk mengatasi masalah gangguan metabolik pada diabetes. Gerakan yoga pranayama (kontrol pernafasan), asana (panas tubuh), meditasi (relaksasi pikiran). Jenis gerakan asana, pranayama dan kriya (proses penjernihan) penting untuk mengatasi masalah stres dan mengubah gaya hidup pada pasien dengan diabetes melitus. Hasil penelitian Agte (2004) menunjukkan bahwa gerakan utama dari yoga yaitu asana memberikan dampak perubahan glukosa dan konduktifitas saraf. Asana mempunyai keuntungan dalam mengontrol glycemic dan meningkatkan konduktifitas saraf terutama pada diabetic neuropatic dengan mekanisme relaksasi pikiran.

Latihan Yoga berdasarkan penelitian Venugopal (2017) dapat mengontrol gula darah dan dapat menurunkan BB, tekanan darah, lipid profile, stress oxidative dan level cortisol. Selain itu latihan yoga dapat mengatasi masalah pada diabetes type II dengan mengontrol gangguan toleransi glukosa. Durasi latihan yoga yang dilakukan secara teratur menunjukkan hasil lebih efektif daripada latihan fisik lainnya. Perubahan positif tersebut terjadi melalui 2 jalur yaitu hypothalamic pituitary adrenal (HPA) axis atau mengurangi aktivasi sistem symphato-adrenal. Dimana aktifasi HPA axis dan sistem symphato adrenal dapat meningkatkan resistensi insulin, inhibisi pelepasan insulin dan meningkatkan produksi glukosa hepatik. Masalah kesehatan yang dialami oleh responden dapat menyebabkan terhentinya latihan yoga secara teratur, akan tetapi latihan yoga yang dilakukan selama 10 hari teratur dapat menurunkan gula darah puasa. Di sisi lain dampak dari gerakan yoga seperti peregangan (streching) dapat meningkatkan sensisivitas glukosa dan meningkatkan clearance glukosa. Gerakan asana selama yoga diduga sangat berhubungan dengan penurunan glukosa ini karena stimulasi peregangan otot dan jaringan selama latihan yoga. Oleh sebab itu naik turunnya kadar gula darah dipengaruhi oleh keteraturan dalam melakukan gerakan yoga untuk menstimulasi organ tubuh seperti pankreas.

Gerakan - gerakan Yoga terdiri dari beberapa tahapan yaitu mulai dari pemanasan, gerakan inti, olah nafas dan berakhir dengan meditasi. Pemanasan dilakukan kurang lebih selama 15 menit, gerakan inti selama 30 menit dan diakhiri dengan relaksasi selama 15 menit (Wirawanda, 2014). Semua tahapan gerakan dilakukan secara intensif, ritmik, rileks serta tidak menimbulkan cedera fisik. Ciri - ciri inilah yang membuat latihan fisik yoga sama dengan olahraga aerobik yaitu dilakukan secara intensif, intensitas rendah, ritmik dengan durasi 30-60 menit (Waspadji, 2011). Untuk itu hal ini menjadi penting jika latihan dilakukan secara teratur untuk mendapatkan hasil yang maksimal.

\section{KESIMPULAN}

Prevalensi Diabetes mellitus tipe II ini diperkirakan terus meningkat diikuti dengan tinginya angka obesitas. Yoga merupakan olahraga aerobik yang mampu memberikan perubahan yang bermakna pada kadar gula darah sewaktu (Hedge, 2011), kelompok yang mendapat terapi tambahan yoga mengakibatkan penurunan gula darah yang signifikan. Intervensi Yoga untuk pencegahan dan pengibatan DM tipe II merupakan pengobatan yang hemat biaya dan bebas efek samping. Latihan fisik Yoga bisa digunakan sebagai latihan fisik yang efektif untuk 
mengontrol atau menurunkan kadar gula darah sewaktu pada diabetes mellitus tipe 2.

\section{DAFTAR PUSTAKA}

Agte, vaishali \& Tarwadi, Kirtan. (2004). Sudarshan Kriya Yoga for Treating Type 2 Diabetes. Alternative \& Complementary Therapies. 220-222.

Association, A. D. (2015). Standards Of Medical Care In Diabetes - 2015. Clinical And Applied Research and Education, S1-S94.

Betteng, R. d. (2014). Analisis Faktor Resiko Penyebab Terjadinya Diabetes melitus Tipe 2 Pada Wanita Usia Produktif. eBiomedik, 404.

Bindra, M. N. (2013). Influence of Pranayamas and Yoga Asanas On Blood Glucose, Lipid Profile and HBA1C In Type 2 Diabetes. International Journal Of Pharma and Bio Science, 169 - 172.

Greenstein, B. \&. (2010). At a Glance Sistem Endokrin. Jakarta: Erlangga.

Islafatun, N. (2014). The magic Movements Of Yoga ; Hal - hal yang perlu dipersiapkan dalam yoga; Jenis - jenis yoga dan gerakannya; berbagai manfaat fisik dan spiritual dengan yoga; Yoga untuk anak; Yoga untuk ibu hamil . Jogjakarta: Trans Idea Publising.

Kondza, S. I. (2009). Community Based Yoga Classes for type 2 dabetes: an exploratory randomised cotrolled trial. BMC Health Services Research.
McPhee J, S. \&. (2011). Patofisiologi Penyakit ; Pengantar Menuju Kedokteran Klinis. Jakarta: EGC.

Notoatmojo, S. (2012). Metodologi Penelitian Kesehatan . Jakarta: Rineka Cipta.

Price, A. S. (2006). Patofisiologi; Konsep kilinis Proses - Proses Penyakit . Jakarta: EGC.

RI, K. K. (2013, Agustus Senin). Situasi dan Analisis Diabetes. Jakarta, DKI, Indonesia.

Setiadi, S. d. (2014). IImu Penyakit Dalam. Jakarta: Interna Publishing.

Sherwood, L. (2014). Fisiologi manusia, Dari sel ke Sistem. Jakarta: EGC.

Sivananda, S. (2006). Yoga Asanas. Semarang: P.T Mandira.

Sri K.V, S. K. (2014). Impact Of Pranayama and Amla, an approach towards the Control of Diabetes Melitus. International Journal of PharmTech Research, $1157-1161$.

Suddarths, B. a. (2007). Medical Surgical Nursing.

Sui, K. C. (2010). Keajaiban Penyembuhan Prana. Manila: Surya Cahaya.

Surya B. Dharma \& Harlinawati, Y. (2006). Taklukan Diabetes dengan Yoga. Jakarta: Puspa swara.

Susilo, H. W. (2013). Penelitian Dalam IImu Keperawatan ; Pemahaman Dan Penggunaan metode Kuantitatif Serta Aplikasi Dengan Program SpSS \& Lisrel. Jakarta: In Media. 
Susilo, H. W. (2014). Biostatistika lanjut dan Aplikasi Riset ; Kajian Medikal Bedah pada IImu Keperawatan dengan Analisis Uji Beda, Regresi Linear Berganda dan Regresi Logistik Aplikasi Program SPSS. Jakarta: Trans Info Media.

Syahdrajat, T. (2012). Panduan Menulis Tinjauan Pustaka, Laporan Kasus dan Artikel Penelitian di Jurnal Kedokteran . Jakarta: Dian Rakyat.

Tanner, F. J. (1989). Inggris: Castelemead Publication.

Thibodeau, A. G. ( Sixth Edition ). Anatomy \& Physiology. Mosby Elsevier.

Venugopal,V; Rathi,Amit; Raghuram,Nagarthna. (2017). Effect of Short-term Yoga-based Lifestyle Intervention on Plasma Glucose Levels in Individuals with Diabetes and Pre-Diabetes in the Community. Diabetes \&
Metabolic Syndrome: Clinical Research \& Reviews.

Vennila, S. d. (2014). Efficacy Of Aqueous Extract of Helicteres isora on Glucosa level Type 2, Diabetic Patients Practicing Yoga. Diabetes Metab, 21556156.

Waspadji, S. \&. (2011). Aspek Biomolekular Diabetes Melitus II. Jakarta: Fakultas Kedokteran Universitas Indonesia.

Wild, S. (2015, Oktober Rabu ). Global Prevalence of Diabetes. Estimates for the year 2000 and projection for 2030, hal. 10471053.

Wilson, D. H. (2012). Wongs Clinical Manual of Padiatric Nursing. America: Elsevier.

Wirawanda, Y. (2014). Kedasyatan Terapi Yoga. Jakarta: Padi. 